\title{
In hospital cost assessment and prevalence of Total Hip Arthroplasty in China: A 10-years real-world study
}

\author{
Mingcheng Yuan \\ Sichuan University West China Hospital \\ Hirose Shakya \\ Sichuan University West China Hospital \\ Hao-Yang Wang \\ Sichuan University West China Hospital \\ Zhenyu Luo \\ Sichuan University West China Hospital \\ Ke Xiao \\ Sichuan University West China Hospital \\ Zong-ke Zhou ( $\square$ zhouzongke@scu.edu.cn ) \\ Sichuan University West China Hospital https://orcid.org/0000-0002-9037-4756
}

\section{Research article}

Keywords: Total hip arthroplasty, In hospital cost, Total hospital stay

Posted Date: July 14th, 2020

Dol: https://doi.org/10.21203/rs.3.rs-41296/v1

License: (9) (1) This work is licensed under a Creative Commons Attribution 4.0 International License. Read Full License 


\section{Abstract}

Background: The rising costs of total hip arthroplasty (THA) have resulted in a substantial economic burden to the people of China and Chinese health-care system. The objective of this study was to assess the in-hospital costs associated with primary total hip arthroplasty and efforts to contain these costs by ascertaining factors responsible for the rise in cost.

Methods: In-hospital costs of 8111 patients (3878 male and 42337 female) who underwent elective primary unilateral hip arthroplasty were extracted from our institution between January 2009 and December 2018 and reviewed. The number of yearly procedures was recorded. All hospital related charges were categorized into 9 groups based on hospital-based supplies and services. The correlation between total in hospital cost and 9 groups were assessed using Pearson's coefficient. The same method was used for correlating hospital stay and bed charge.

Results: The substantial rise in yearly procedure volume was observed. The number of procedures had risen from 306 in 2009 to 1024 in 2018 , an incidence increased by more than threefold. The average cost for THAs procedure was $¥ 53468.03 \pm 4833$ in 2009 that rose by approximately $10 \%$ in 2018 ( $¥ 58593.62 \pm 4801$ ). The mean cost observed over the study period was $¥ 62980.21 \pm 6314.673$. The charges analyzed in all categories expect the hospital bed cost increased during the study period. The joint implant was the most expensive supply item contributing $75 \%$ of the total inhospital cost. Labor cost covered only 10\% and bed charge $0.93 \%$ of the total charge. The rise in total in-hospital cost strongly correlated with increase in implant cost (Pearson's correlation $(r)=0.908, a>0.05$ ). The mean total hospital stays declined from $16.11 \pm 8.19$ days in 2009 to 6.13 \pm 2.65 days in 2018 . The mean post-operative stay had also reduced from $9.12 \pm 4.88$ to a third (3.01 \pm 1.80$)$ during the same period. The hospital cost and bed charge also strongly correlated $(r=0.931, a>0.05)$

Conclusions: The number of hip arthroplasty procedures performed annually in China is growing rapidly. An incidence rose by threefold over 10year period in the present study and we predict an unprecedented rise in the incidence in coming years due to an aging population and improving economic conditions in China. The hospital stay was significantly reduced and early discharge within 3 days postoperatively was a noteworthy outcome. Implant cost remained the largest single expense. As a result, some patients who are medical candidates for total joint arthroplasty, may not have access to care due to relatively high financial barrier. Hence it is important to note that significant patient benefits may be realized by efforts to reduce the cost of the prosthesis in China.

\section{Background}

Total hip arthroplasty (THA) is proven effective treatment for advanced arthritis of the hip that has not responded to non-operative treatment. The efficacy in relieving pain and improving physical function in patients with end-stage arthroplasty is greater than $90 \%$ [ $1-5]$. It is also one of the safest and most cost-effective orthopaedic surgical procedures [6] and is often performed for patients with symptomatic bilateral arthritis of the hip [7]. Less than $10 \%$ of THAs ever require revision surgery, and currently nearly 1 million Americans are better able to walk and work because of the prosthetic hip joint that has replaced their own diseased joint [8].

More than 800, 000 THA and TKA are performed annually in the United States [9]. According to data from the United States published in 2009, the incidence of joint arthroplasty was 66 THA and 155 TKA per 10000 people [10]. However, the data from China are drastically different; as recently as 2004, only 1 person per 10000 underwent joint arthroplasty [11]. Because of an aging population and improving economic conditions in China, the demand for joint arthroplasty has increased. In a recent study about 50000 hip or knee arthroplasties are annually performed in China; this number is increasing every year; the number of surgeries continues to rise annually by 15\% [12].

Despite this dramatic increase, the high cost of surgical treatment and relatively low insurance reimbursement has likely contributed to some patients forging joint arthroplasty. This financial barrier may limit access to care and has potentially decreased the quality of life for patients with arthritis, increased the burden on society to care for these individuals, and led to a decrease in the productivity of the labor force in China. Furthermore, it may have also negatively impacted the advancement of medical services in China [13].

Concerns exist as financial constraints potentially limit access to joint arthroplasty in China, there have been very few cost analyses of joint arthroplasty surgery reported from China. This retrospective study designed was to analyze cost fluctuation of unilateral hip arthroplasty during 10 years period that were performed our institution and to ascertain an annual procedure volume (i.e., incidence) as many studies are involved in the descriptive epidemiology of total hip replacement focusing almost exclusively on annual procedure volumes [14-17].

\section{Material And Methods}

The medical and financial records of patients who had received elective primary unilateral hip arthroplasty in Joint Surgery Department, in our institution between January 2009 to December 2018 were extracted and reviewed. The study protocol was approved by The Medical Ethics Committee of the Hospital. The surgeries performed, were by five high volume arthroplasty surgeons (at least 50 THA per year). This analysis was entirely retrospective, which minimized any surgical or clinical management bias on the part of the physicians associated with this study. 
Patients $\geq 17$ years of age who underwent primary THA procedure were considered for this study. Research variables included sex ratio, procedure volume, hospital stay and annual total expenses in different year as to make the hospitalizations comparable in terms of cost.

Patients with the following criteria were excluded in our analysis. Fracture (trauma), revision, emergency, surface arthroplasty, bilateral procedures, complex cases requiring additional procedures, severity of comorbid disease states and bone graft. Cases where the patients were roomed on the VIP ward that increased the hospital room fees were also excluded.

Following these exclusions, total of 8111 patients were identified. Their records available in OR/OPD registry were retrieved and reviewed. The data generated were subjected for analysis.

\section{Financial Data}

All hospital related charges for each patient were collected and assigned to 9 categories based on hospital-based supplies and services. These supplies and services were pharmacy, prosthesis, surgery, anesthesia, laboratory tests, inspection fee, medical fee, nursing fee and hospital charge. Use of implant type and price, types of drug used (intravenous vs oral), additional laboratory test performed, extra fee for additional tests and services provided. Post-operative follows up procedure as designed by "Continuous medical services" were also documented.

The costs and charges were averaged among all patients considered in each year, and the averages were then compared between 2009 and 2018. Charge-to-total cost ratios for each category were also determined and analyzed. The charge to total cost ratios expressed as the percentage markup from was also calculated. These charge-to-cost ratios used to estimate costs based on charge data is a reliable and accepted method of reporting hospital cost [18]. Labor cost as defined by Zhang et al., [13] the total charges for the surgery, nursing fee, and inspection fee was also calculated.

\section{Statistical Analysis}

Each categorical variable was reported as mean and standard deviation. Karl Pearson's coefficient (r) were calculated to ascertain the correlation between different cost variables such as implant vs in-hospital cost; the length of stay vs bed cost using SPSS version 21.0 (SPSS Inc., Chicago, IL, USA).

\section{Result}

During 10-year period from Jan 2009 to Dec2018, 8111 patients of both sex who underwent primary, unilateral THA were eligible and included. Male constituted 48\% (3878) and female 52\% (4233). The higher prevalence was seen among women than among men (Table 1).

Table 1

Age and Sex ratio

\begin{tabular}{|llll|}
\hline Sex & Number & Percent (\%) & Age \\
\hline Male & 3878 & 48 & $53.118 \pm 13.516$ \\
Female & 4233 & 52 & $57.187 \pm 13.513$ \\
\hline Total & 8111 & & \\
\hline
\end{tabular}

The procedure volume had been increasing yearly (Chart 1). There were only 306 surgeries performed in 2009 . This number had risen significantly and to more than three-fold in 2018 (1040). The maximum surgeries were done in 2017(1186).

The decreasing trend of hospital stay was seen in the present study (Table 2). The mean total hospital stays declined in subsequent years from $16.11 \pm 8.19$ days in 2009 to $6.13 \pm 2.65$ days in 2018 . The mean post-operative stay had also reduced from $9.12 \pm 4.88$ days in 2009 to a third in 2018 (3.01 \pm 1.80$)$. The Pearson's coefficient between hospital cost and bed charge and found to be strongly correlated $(r=0.931, a>0.05)$. 
Table 2

Total in-hospital stay and post-operative stay

\begin{tabular}{|lll|}
\hline Year & Total in-hospital stay in days & Post-operative hospital stays \\
\hline 2009 & $16.11 \pm 8.19$ & $9.12 \pm 4.88$ \\
\hline 2010 & $14.86 \pm 7.39$ & $8.38 \pm 4.70$ \\
\hline 2011 & $11.86 \pm 5.87$ & $7.11 \pm 3.99$ \\
\hline 2012 & $11.94 \pm 5.22$ & $6.88 \pm 3.96$ \\
\hline 2013 & $11.36 \pm 4.89$ & $6.46 \pm 3.71$ \\
\hline 2014 & $10.91 \pm 5.92$ & $6.42 \pm 4.16$ \\
\hline 2015 & $10.38 \pm 3.46$ & $5.60 \pm 2.52$ \\
\hline 2016 & $9.11 \pm 4.12$ & $4.52 \pm 2.77$ \\
\hline 2017 & $7.53 \pm 2.98$ & $3.57 \pm 2.12$ \\
\hline 2018 & $6.13 \pm 2.65$ & $3.01 \pm 1.80$ \\
\hline
\end{tabular}

Over the 10-year period (2009-2018), average total charges of hospitalization for patients undergoing unilateral THA was $¥ 62980.21 \pm 6314$.

673. The average cost for THAs performed in 2009 was $¥ 53468.03 \pm 4833$. For the same procedure in 2018 , total cost averaged $¥ 58593.62 \pm 4801$. The highest cost was observed in 2013 ( $¥ 73620.21)$ and lowest in 2009 ( $¥ 53468.02)$ and the total cost fluctuated slightly in the study period.

The implant cost was the highest among all categories ( $¥ 47287.604 \pm 7474.480$ ). The cost fluctuated yearly with record high in 2013 ( $¥ 58625.772$ \pm 226.313 ) and lowest in 2018 ( $¥ 37865.900 \pm 20019.360)$. Similarly, surgery charges were the second highest category ( $¥ 4661.812 \pm 1806.625)$ and followed by pharmacy ( $¥ 3951.546 \pm 381.912)$.

The most significant increases in hospitalization cost involved the surgery and medical fee. The surgical fee had risen from $¥ 3454.061 \pm 1364.985$ in 2009 to $¥ 7791.449 \pm 2205.676$ in 2018 . We observed surgery fee more than doubled and fourfold increase in medical fee ( $¥ 647.6416 \pm 430.323$ in 2009 and $¥ 2671.645 \pm 323.461$ in 2018 ) over 10 -year period.

Increase in charge for anesthesia, lab fee and nursing fee were also observed. Although rise in cost was observed yearly in all categories during the study period, an exception was seen in bed charge which showed a three-fold decline in cost from $¥ 1032.68 \pm 479.70$ (2009) to $¥ 327.1 \pm 151.73$ (2018). Itemized lists of charges assigned into 9 charge categories and their total costs for each year are presented in Table 3. 
Table 3

Cost consistence for patients of primary, unilateral THA from 2009 to 2018 [ in RMB yuan ( $¥$ ]

\begin{tabular}{|c|c|c|c|c|c|c|c|c|c|c|}
\hline Year & Pharmacy & Prosthesis & Surgery** & $\underset{* \star}{\text { Anesthesia }}$ & Lab tests & $\begin{array}{l}\text { Inspection } \\
\text { Fee }\end{array}$ & $\begin{array}{l}\text { Medical } \\
\text { Fee }\end{array}$ & $\begin{array}{l}\text { Nursing } \\
\text { fee\# ** }\end{array}$ & $\begin{array}{l}\text { Bed } \\
\text { charge }\end{array}$ & Total \\
\hline 2009 & $\begin{array}{l}3550.101 \\
\pm \\
1421.036\end{array}$ & $\begin{array}{l}40649.154 \\
\pm \\
16666.176\end{array}$ & $\begin{array}{l}3454.061 \\
\pm \\
1364.985\end{array}$ & $\begin{array}{l}1256.58 \pm \\
373.28\end{array}$ & $\begin{array}{l}851.347 \pm \\
252.398\end{array}$ & $\begin{array}{l}1713.050 \\
\pm \\
862.0731\end{array}$ & $\begin{array}{l}647.641 \\
\pm 430.323\end{array}$ & $\begin{array}{l}313.408 \\
\pm \\
239.1937\end{array}$ & $\begin{array}{l}1032.68 \\
\pm 479.70\end{array}$ & $\begin{array}{l}53468.03 \\
\pm 4833\end{array}$ \\
\hline 2010 & $\begin{array}{l}3546.289 \\
\pm \\
1485.736\end{array}$ & $\begin{array}{l}47693.245 \\
\pm \\
16961.307\end{array}$ & $\begin{array}{l}3720.898 \\
\pm 1369.01\end{array}$ & $\begin{array}{l}1137.63 \pm \\
343.94\end{array}$ & $\begin{array}{l}825.579 \pm \\
271.241\end{array}$ & $\begin{array}{l}1742.598 \\
\pm \\
823.9992\end{array}$ & $\begin{array}{l}635.1895 \\
\pm 183.508\end{array}$ & $\begin{array}{l}284.875 \\
\pm \\
87.9627\end{array}$ & $\begin{array}{l}697.00 \\
\pm 320.21\end{array}$ & $\begin{array}{l}60283.31 \\
\pm 6610\end{array}$ \\
\hline 2011 & $\begin{array}{l}3584.228 \\
\pm \\
1325.1782\end{array}$ & $\begin{array}{l}57632.569 \\
\pm \\
21526.307\end{array}$ & $\begin{array}{l}3857.549 \\
\pm \\
1608.538\end{array}$ & $\begin{array}{l}1339.75 \pm \\
613.16\end{array}$ & $\begin{array}{l}849.90 \pm \\
287.42\end{array}$ & $\begin{array}{l}1736.70 \pm \\
821.15\end{array}$ & $\begin{array}{l}665.370 \\
\pm 392.537\end{array}$ & $\begin{array}{l}368.342 \\
\pm \\
164.0005\end{array}$ & $\begin{array}{l}634.40 \\
\pm 271.13\end{array}$ & $\begin{array}{l}70668.81 \\
\pm 5311\end{array}$ \\
\hline 2012 & 3564.0425 & $\begin{array}{l}56115.782 \\
\pm \\
20498.297\end{array}$ & $\begin{array}{l}4016.250 \\
\pm \\
1712.345\end{array}$ & $\begin{array}{l}1187.75 \pm \\
422.71\end{array}$ & $\begin{array}{l}856.35 \pm \\
245.25\end{array}$ & $\begin{array}{l}2372.35 \pm \\
1085.22\end{array}$ & $\begin{array}{l}1625.616 \\
\pm 616.275\end{array}$ & $\begin{array}{l}348.82 \pm \\
246.1033\end{array}$ & $\begin{array}{l}698.10 \\
\pm 289.68\end{array}$ & $\begin{array}{l}70785.06 \\
\pm 4368\end{array}$ \\
\hline
\end{tabular}

\begin{tabular}{|c|c|c|c|c|c|c|c|c|c|c|}
\hline 2013 & $\begin{array}{l}4296.622 \\
\pm \\
1207.044\end{array}$ & $\begin{array}{l}58625.772 \\
\pm \\
22666.313\end{array}$ & $\begin{array}{l}3782.64 \\
\pm \\
1171.292\end{array}$ & $\begin{array}{l}1089.404 \\
\pm 325.132\end{array}$ & $\begin{array}{l}857.250 \pm \\
250.528\end{array}$ & $\begin{array}{l}2453.644 \\
\pm \\
1172.961\end{array}$ & $\begin{array}{l}1635.444 \\
\pm 658.123\end{array}$ & $\begin{array}{l}260.528 \\
\pm \\
86.4027\end{array}$ & $\begin{array}{l}618.90 \\
\pm 247.75\end{array}$ & $\begin{array}{l}73620.21 \\
\pm 5669\end{array}$ \\
\hline 2014 & $\begin{array}{l}4316.698 \\
\pm \\
1247.991\end{array}$ & $\begin{array}{l}44455.289 \\
\pm \\
15720.524\end{array}$ & $\begin{array}{l}3645.942 \\
\pm \\
1271.209\end{array}$ & $\begin{array}{l}1034.00 \pm \\
158.559\end{array}$ & $\begin{array}{l}1211.200 \pm \\
284.223\end{array}$ & $\begin{array}{l}2420.650 \\
\pm \\
1041.812\end{array}$ & $\begin{array}{l}1689.397 \\
\pm 752.483\end{array}$ & $\begin{array}{l}248.978 \\
\pm \\
49.6994\end{array}$ & $\begin{array}{l}547.15 \\
\pm 219.01\end{array}$ & $\begin{array}{l}59569.31 \\
\pm 6210\end{array}$ \\
\hline 2015 & $\begin{array}{l}4357.750 \\
\pm \\
1442.455\end{array}$ & $\begin{array}{l}43483.553 \\
\pm \\
15433.623\end{array}$ & $\begin{array}{l}3804.021 \\
\pm \\
1303.393\end{array}$ & $\begin{array}{l}995.30 \pm \\
118.23\end{array}$ & $\begin{array}{l}1246.5 \pm \\
275.102\end{array}$ & $\begin{array}{l}2591.25 \pm \\
1130.55\end{array}$ & $\begin{array}{l}1652.710 \\
\pm 601.319\end{array}$ & $\begin{array}{l}288.716 \\
\pm \\
42.2537\end{array}$ & $\begin{array}{l}473.15 \\
\pm 165.83\end{array}$ & $\begin{array}{l}58892.95 \\
\pm 8552\end{array}$ \\
\hline 2016 & $\begin{array}{l}4278.608 \\
\pm \\
1325.608\end{array}$ & $\begin{array}{l}43079.837 \\
\pm \\
14858.565\end{array}$ & $\begin{array}{l}4218.096 \\
\pm \\
1682.629\end{array}$ & $\begin{array}{l}1033.50 \pm \\
99.49\end{array}$ & $\begin{array}{l}1250.692 \pm \\
278.7723\end{array}$ & $\begin{array}{l}2658.90 \pm \\
1274.07\end{array}$ & $\begin{array}{l}1656.028 \\
\pm 517.339\end{array}$ & $\begin{array}{l}359.808 \\
\pm \\
98.6167\end{array}$ & $\begin{array}{l}417.10 \\
\pm 150.96\end{array}$ & $\begin{array}{l}58952.57 \\
\pm 4899\end{array}$ \\
\hline 2017 & $\begin{array}{l}4302.87 \pm \\
1246.03\end{array}$ & $\begin{array}{l}43274.944 \\
\pm \\
14673.378\end{array}$ & $\begin{array}{l}8327.221 \\
\pm \\
2411.914\end{array}$ & $\begin{array}{l}1339.95 \pm \\
95.38\end{array}$ & $\begin{array}{l}1283.05 \pm \\
314.42\end{array}$ & $\begin{array}{l}2642.575 \\
\pm \\
1299.765\end{array}$ & $\begin{array}{l}2678.884 \\
\pm \\
746.6973\end{array}$ & $\begin{array}{l}751.682 \\
\pm \\
211.322\end{array}$ & $\begin{array}{l}367.05 \\
\pm 136.62\end{array}$ & $\begin{array}{l}64968.23 \\
\pm 5037\end{array}$ \\
\hline
\end{tabular}

\# includes default plus custodial fee (100 RMB yuan)

*Oral Topical Tranexamic Acid (TXA) was started in2018 replacing moreexpensive intravenousTXA that had been using since 2013.

** The policy of hospital and the Ministry of Health governs the rate of Surgery, Anesthesia and Nursing so the cost in these categories changes accordingly.

*** Additional preoperative blood tests such as thyroid hormones (T3 + T4 + TSH + FT3 + FT4) and cardiac markers were started since 2014 .

$\star \star \star \star$ Color Doppler ultrasound of the urinary system and ultrasonic cardiogram were started preoperatively in 2012. From 2015, lower limb vascular Color Doppler ultrasound were added on the day of discharge. Also, arrangement had been made to receive one more lower limb vascular ultrasound if the patients stay in hospital for more than a week after surgery.

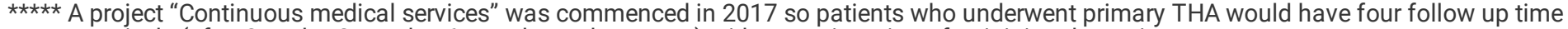
postoperatively (after 3weeks, 2months, 6 months and one year) without registration after joining the project. 


\begin{tabular}{|c|c|c|c|c|c|c|c|c|c|c|}
\hline Year & Pharmacy & Prosthesis & Surgery** & $\underset{\star \star}{\text { Anesthesia }}$ & Lab tests & $\begin{array}{l}\text { Inspection } \\
\text { Fee }\end{array}$ & $\begin{array}{l}\text { Medical } \\
\text { Fee }\end{array}$ & $\begin{array}{l}\text { Nursing } \\
\text { fee\# } * *\end{array}$ & $\begin{array}{l}\text { Bed } \\
\text { charge }\end{array}$ & Total \\
\hline \multirow[t]{2}{*}{2018} & & 37865.900 & 7791.449 & \multirow{2}{*}{$\begin{array}{l}1332.60 \pm \\
82.67\end{array}$} & \multirow{2}{*}{$\begin{array}{l}1259.35 \pm \\
325.89\end{array}$} & \multirow{2}{*}{$\begin{array}{l}2820.600 \\
\pm \\
1235.403\end{array}$} & \multirow{2}{*}{$\begin{array}{l}2671.645 \\
\pm 323.461\end{array}$} & \multirow{2}{*}{$\begin{array}{l}806.72 \pm \\
213.8132\end{array}$} & \multirow{2}{*}{$\begin{array}{l}327.10 \\
\pm 151.73\end{array}$} & \\
\hline & $\pm \frac{ \pm}{1225.394}$ & 20019.360 & 2205.676 & & & & & & & \pm 4801 \\
\hline \multirow{2}{*}{$\begin{array}{l}\text { Mean } \\
(x)\end{array}$} & \multirow{2}{*}{$\begin{array}{l}3951.546 \\
\pm 381.912\end{array}$} & & $\begin{array}{l}4661.812 \\
+\end{array}$ & \multirow{2}{*}{$\begin{array}{l}1174.6464 \\
\pm 136.187\end{array}$} & 1049.121 & 2315.231 & 1555.792 & 403.187 & 581.263 & 62980.21 \\
\hline & & \pm 7474.48 & 1806.625 & & $\stackrel{ \pm}{212.793034}$ & \pm 423.688 & \pm 746.85 & $\stackrel{ \pm}{202.658}$ & $\stackrel{ \pm}{206.922}$ & $\stackrel{ \pm}{6314.673}$ \\
\hline \multicolumn{11}{|c|}{ \# includes default plus custodial fee (100 RMB yuan) } \\
\hline \multicolumn{11}{|c|}{ *Oral Topical Tranexamic Acid (TXA) was started in2018 replacing moreexpensive intravenousTXA that had been using since 2013.} \\
\hline \multicolumn{11}{|c|}{$\begin{array}{l}\text { ** The policy of hospital and the Ministry of Health governs the rate of Surgery, Anesthesia and Nursing so the cost in these categories changes } \\
\text { accordingly. }\end{array}$} \\
\hline \multicolumn{11}{|c|}{ *** Additional preoperative blood tests such as thyroid hormones (T3 + T4 + TSH + FT3 + FT4) and cardiac markers were started since 2014.} \\
\hline \multicolumn{11}{|c|}{$\begin{array}{l}\star * \star \star \text { Color Doppler ultrasound of the urinary system and ultrasonic cardiogram were started preoperatively in 2012. From } 2015 \text {, lower limb } \\
\text { vascular Color Doppler ultrasound were added on the day of discharge. Also, arrangement had been made to receive one more lower limb } \\
\text { vascular ultrasound if the patients stay in hospital for more than a week after surgery. }\end{array}$} \\
\hline
\end{tabular}

Various types of implant were used in different years of the study period. Big femoral head and mental on mental implant was used in 2009 while in 2010, Mental on cream implant. Similarly, an expensive Cream femoral head and cream on cream implant was started from 2011 to 2013. Significant rise in total in-hospital cost were recorded during that period. The price of the implant decreased in 2014 owing to decrease in total hospital cost. In 2018, some implants were provided free of cost under GCP projects so overall cost of implant decreased. The rise in total inhospital cost and implant cost were analyzed and strong correlation was found between them (Pearson's correlation $(r)=0.908, a>0.05$ ).

Table 4 depicts percentage of cost in each category. The top 3 charges, calculated as a mean percentage of the total charges were prosthesis charges (most expensive) $74.83 \pm 5.615$, surgery charges (second most expensive) $7.46 \pm 2.997$ and pharmacy (third most expensive) $6.3 \pm 0.884$. The contribution of charges under the other 6 categories in the present study were $3.7 \%$, inspection fee, $2.48 \%$ medical fee, $1.87 \%$ anesthesia, $1.68 \%$ lab tests, $0.93 \%$ bed charge, and $0.64 \%$ nursing fee. Bed charge and nursing fee amount to only a fraction of percentage of the total charges.

Table 4

Categorical representation of cost by percentage.

\begin{tabular}{|llllllllll|}
\hline Year & Pharmacy & Prosthesis & Surgery & Anesthesia & Lab tests & Inspection Fee & Medical Fee & Nursing fee & Bed charge \\
\hline $\mathbf{2 0 0 9}$ & 6.6 & 76 & 6.46 & 2.35 & 1.59 & 3.2 & 1.21 & 0.58 & 1.93 \\
\hline $\mathbf{2 0 1 0}$ & 5.8 & 79.1 & 6.16 & 1.89 & 1.37 & 2.89 & 1.05 & 0.48 & 1.16 \\
\hline $\mathbf{2 0 1 1}$ & 5 & 81.56 & 5.45 & 1.89 & 1.2 & 2.45 & 0.94 & 0.52 & 0.89 \\
\hline $\mathbf{2 0 1 2}$ & 5 & 79.27 & 5.67 & 1.67 & 1.2 & 3.35 & 2.29 & 0.49 & 0.98 \\
\hline $\mathbf{2 0 1 3}$ & 5.8 & 79.63 & 5.13 & 1.47 & 1.16 & 3.33 & 2.22 & 0.35 & 0.84 \\
\hline $\mathbf{2 0 1 4}$ & 7.24 & 74.62 & 6.12 & 1.73 & 2.03 & 4.06 & 2.83 & 0.41 & 0.91 \\
\hline $\mathbf{2 0 1 5}$ & 7.39 & 73.83 & 6.45 & 1.69 & 2.11 & 4.39 & 2.8 & 0.49 & 0.8 \\
\hline $\mathbf{2 0 1 6}$ & 7.25 & 73.07 & 7.15 & 1.75 & 2.12 & 4.51 & 2.8 & 0.61 & 0.7 \\
\hline $\mathbf{2 0 1 7}$ & 6.62 & 66.6 & 12.81 & 2.06 & 1.97 & 4.06 & 4.12 & 1.15 & 0.56 \\
\hline $\mathbf{2 0 1 8}$ & 6.34 & 64.62 & 13.29 & 2.27 & 2.14 & 4.81 & 4.55 & 1.37 & 0.55 \\
\hline $\begin{array}{l}\text { Mean } \\
(\mathbf{x})\end{array}$ & $\mathbf{6 . 3 0 4}$ & $\mathbf{7 4 . 8 3}$ & $\mathbf{7 . 4 6 9}$ & 1.877 & 1.689 & 3.705 & 2.481 & 0.645 & 0.932 \\
& $\mathbf{\pm}$ & \pm 5.615128 & \pm 2.997879 & \pm 0.277531 & \pm 0.42574 & \pm 0.771092 & \pm 1.221788 & \pm 0.336526 & \pm 0.396731 \\
\hline
\end{tabular}

Labor cost (the charge for nursing, surgery, and medical) covered only about $10 \%$ of the total charge. The bed charge constituted only a fraction of the total cost with lowest cost in 2019 (0.55\%) and average of 0.932 of overall total cost. 


\section{Discussion}

Replacement of arthritic joints is one of the most successful medical advances of the last 50 years. These operations are associated with low rates of complications; hip and knee reconstructions are durable for 10 to 20 years [19]; and total hip arthroplasty is more cost effective than medical treatment of hypertension, coronary artery bypass, hemodialysis, and liver transplantation [20-23]. It has drastically improved the productivity and quality of life for millions of Americans [18] as it can predictably relieve pain, increase joint motion, and improve function to meet patients' expectations, the large number of Americans have benefited from these procedures [24]. Consistent with its clinical success, the prevalence of TJA is increasing in the United States as the population increases and ages and as elderly Americans refuse to accept disability associated with arthritic joints and desire to be active in their senior years [19], living with a total joint replacement is a remarkably common condition in the United States [24].

Between 2002 and 2004, the prevalence of hip and knee replacements increased 16.2\% to 884,400 procedures annually [24]. Kremer et. al, reported these prevalence estimates corresponded to 2.5 million individuals (1.4 million women and 1.1 million men) with total hip replacement in the United States in 2010 [25]. We also observed prevalence high among women than men (52\% vs 48\%). Our findings were in consistence with the study by Kremer et al. where they found the higher prevalence of severe hip and knee arthritis in women [25] and indicated that the estimated potential need for the osteoarthritis-related arthroplasty was more than twice as great among women as among men [26].So, it is unlikely the prevalence or volume of joint replacement operations in the United States can or will be reduced but will experience unprecedented growth. The prevalence of joint replacement continues to grow and is expected to double by 2026 [27]. By 2030, the demand for primary total hip arthroplasties is estimated to grow by $174 \%$ to 572,000 as projected by Kurtz et al [16]. United States Census Bureau. 2012 projected simply the aging of the population would result in an estimated 11 million individuals with total hip or knee replacement (4 million total hip and 7.4 million total knee) in 2030 (i.e., applying 2010 prevalence to 2030 population estimates [28].

As such, the number of hip arthroplasty procedures performed annually in China is growing rapidly with a $19 \%$ increase per year between 2000 and 2006 [12]. The substantial rise in procedure volume was also observed in our study. The number of procedures had risen from 306 in 2009 to 1024 in 2018 , an incidence rises by threefold. We predict unprecedented rise in the incidence in coming years due to an aging population and improving economic conditions in China.

However, the high cost of this treatment, in today's era of decreasing health care resources and declining reimbursement, has raised doubts as to the financial feasibility of this procedure. Much is currently being done to make total joint arthroplasty more cost effective [17].

The hospital cost of TJA was studied by several investigators during the 1980s and 1990s [18, 29-33]. To date, little data have been published about the finances of total joint arthroplasty in China and the market for these services is in its infancy in China as compared to Western and other foreign countries. Despite the demand, concerns exist that the costs of these procedures may represent a significant barrier to care, with patients potentially unable to gain access to joint arthroplasty [13].

The average hospital cost in 2009 was $¥ 53468.03 \pm 4833$ and that rose by approximately $~ 10 \%$ in 2018 ( $¥ 58593.62 \pm 4801)$. Our observation showed increase in the total hospital costing subsequent years. On average the total hospital cost was $62980.21 \pm 6314.673$. In 2008 and 2009 , Zhang et.al, found the mean total charges for patients undergoing unilateral THA was $¥ 55813$ [13].

All the charges in 9 categories expect the hospital bed cost we analyzed increased during the study period. Surgery fee increased by more than twofold. Alike, anesthesia and nursing fee were also increased by the same ratio. The increase in cost regarding these categories are difficult to explain as these costs governed by hospital policy and the Ministry of Health, Government of China. The labor charges comprising of nursing charges, inspection charges and physician's surgical charges in particular accounted for only approximately $1 / 11$ th of the total charges and were about a1/15th of the prosthesis charges.

The rise in total in-hospital cost was attributed to increase in implant cost. Pearson coefficient was calculated for these two variables and found to be highly correlated $(r=0.908)$. Other factors contributing to rise in cost include additional preoperative blood tests such as thyroid hormones and cardiac markers that were started in 2014. Preoperatively, Color Doppler ultrasound of the urinary system and ultrasonic cardiogram were started in 2012 and from 2015, lower limb vascular Color Doppler ultrasound was added on the day of discharge increased the cost. In addition, arrangement had been made to receive one more lower limb vascular ultrasound if the patients stay in hospital for more than a week after surgery. A project "Continuous medical services" was commenced in 2017 so patients who underwent primary THA would have four follow up time postoperatively (after 3weeks, 2months, 6 months and one year) without registration after paying and joining the project. These added facilities increased the total cost to some extent.

The joint implant is the most expensive supply item for joint replacement[18, 29]. A finding by Healy et. al, in evaluating the hospital cost for THA, the joint implant cost is the largest single expense [19]. It is important to note that the trend was also seen in the present study. Its cost remained the largest single expense in our study constituting about $75 \%$ of the total cost of hip arthroplasty. Comparing these previously published data to the current data, it is apparent that prosthesis costs represent the largest contributor to total costs in the United States, China, and Taiwan. However, the relative cost of the prosthesis in the United States was less than it is in China (70.8\%) and Taiwan (61\%) [13].

Page $7 / 12$ 
The contribution of charges under the other 8 categories in the present study were $7.46 \%$ surgery, $6.3 \%$ pharmacy, $3.7 \%$, inspection fee, $2.48 \%$ medical fee, $1.87 \%$ anesthesia, $1.68 \%$ lab tests, $0.93 \%$ bed charge, and $0.64 \%$ nursing fee. Bed charge and nursing fee constituted only a fraction of percentage of the total charges.

A study by Zhang et.al, [13] in China in 2008 and 2009, the cost distribution at Jishuitan Hospital, Beijing was pharmacy $9.3 \%$, surgery $2.8 \%$, laboratory tests $2.9 \%$ and nursing and bed $1.2 \%$.

More recent data from 2008, derived from Medicare billing in the United States, were as follows: $56 \%$ prosthesis, $4 \%$ nursing fees and hospital bed, $29 \%$ surgery, $4 \%$ pharmacy, $1 \%$ laboratory assays, $2 \%$ radiology, $2 \%$ rehabilitation, and $2 \%$ for other costs [34].

Data from outside the United States have also been previously published. At the Kaohsiung Hospital in Taiwan in 2000 , the cost distribution was $61 \%$ prosthesis, $10 \%$ nursing and hospital rooms, $15 \%$ surgery, $5 \%$ pharmacy, $3 \%$ laboratory tests, $1 \%$ radiology, and $4 \%$ other costs [35]. Somewhat similar result was also found in our study.

Chiu et al, in 2007 compared labor costs between the United States vs China and found it relatively higher in the United states. Labor costs accounted for $50 \%$ of the total costs at University of Texas, $50 \%$ at UCLA, $47 \%$ in Burlington, $25 \%$ Mayo Clinic in the United States in $2007,26 \%$ at Kaohsiung Hospital in Taiwan [35]. Our study showed labor cost constituted only $10 \%$ of the total cost. Our findings were somewhat higher than the study carried by Zhang et al at the Beijing Jishuitan Hospital where they recorded the labor cost accounted for only $4 \%[13]$. Representing costs vs charges, broad comparisons emphasize the same trend as noted from other published studies from the United States; labor costs accounted for the greatest share of total costs, whereas pharmacy and prosthesis costs accounted for a much lower relative percentage of the total than in China. The comparisons noted above also demonstrate that the labor costs in Western countries were significantly higher than the cost of prostheses [13]. Many potential reasons may account for the higher relative labor costs in the United States. First, organized labor markets in the United States may have resulted in higher pay and benefits

The implant cost as being the largest single expense, had direct impact on the total hospital cost. We observed an increase in implant cost from 2011 to 2013 resulted from the rise of total hospital cost which decreased in subsequent years due reduction in implant cost. The cost of the TJA operation cost is reduced when the joint implant cost is reduced, and most authors identified implant cost as an opportunity for cost control [19]. So, the present study suggests control of implant cost is essential to the control of joint replacement hospital cost as both variables are significantly correlated (Pearson coefficient $(r)=0.908)$. Several methods have been described and utilized for controlling the cost of joint replacement implants.

Cost-awareness programs are a good first step in controlling the cost of joint implants [36-39]. Implant standardization or demand matching programs were developed to reduce variation in implant selection and cost for hospitals. Implant standardization for total knee arthroplasty could have saved $8.4 \%$ of in hospital cost [40]. Healy [41,42] and lorio et al [40] demonstrated the cost of hip implants could have been reduced by $25.7 \%$ if an implant standardization program had been applied to total hip arthroplasty.

Negotiated vendor discounts have been more successful in reducing the cost of joint implants and a price cap (a set price the hospital will pay for joint implants) can be successful in reducing joint implant costs if surgeons support the hospital [19]. Joint replacement implant costs cannot be controlled without the cooperation of joint replacement surgeons [19]. Lahey Clinic developed a Single-price/Case-price Implant Purchasing program to buy the "best" implants at the lowest price [41, 42]. Hospital and surgeon cooperation through the Single-price/Case-price Implant Purchasing has been successful in controlling the cost for joint replacement implants. The cost of hip replacement implants decreased $31.8 \%$ with a change in implant vendor [43]. Gain sharing programs have the potential to help hospitals control costs; however, implementation of gain sharing programs will be affected by administrative issues, political barriers, and legal limitations [44]. This program combined with a Single-price/Caseprice Implant Purchasing program trialed at other institutions produced increasingly successful results [19].

There is great variability in joint replacement implants. TJA implants vary in design, material, fixation, and bearing surfaces, which affect their cost [19]. Specific types of innovative implants such as big femoral head and mental on mental implant, the mental on cream implant and cream femoral head and cream on cream implant with different price tag were used in different years in our study. Unfortunately, not all innovations in total joint arthroplasty improve patient outcome, and some innovations have been associated with adverse patient outcomes [19]. However, most, if not all, innovations in total joint arthroplasty have been associated with increased cost [45].

The hospital stays which had been reduced from 16.11 days to 6.13 days. This finding highly correlated with the hospital bed charge (Pearson's coefficient $(r)=0.931)$. We considered it as a significant achievement and we assumed the THA may become a day surgery in near future. Implementation of utilization review strategies has led to significant decreases in the length of stay for elective hospitalizations by Healy and Finn [18] who recently reported a $15 \%$ decrease in hospitalization cost for total Joint arthroplasties over an 8-year period at their center. Some hospitals have used early discharge to skilled nursing facilities and rehabilitation hospitals in order to decrease length of stay, decrease hospital cost and implementation minimally invasive procedures. Healy and lorio attributed cost reduction to the effective control of the volume of services and supplies and an associated decrease in the average length of stay from 18 days in 1983 to 9 days in 1991[19]. 
Several efforts were being made to contain the total cost. Care pathways are being standardized to eliminate unnecessary laboratory tests, medications, and consultations, both before and after surgery [30]. The use of cheap Oral Topical Tranexamic Acid (TXA) in our study substituting intravenous TXA in 2018 as described by Luo et. al,[46] dropped pharmacy cost to some extent. The hospital stay was significantly decreased owing to reduction in bed cost but it had little impact on total in-hospital cost. The potential cost reductions due to reduced utilization are diminishing in our study since more additional tests and facilities were being incorporated rising cost, and utilization may increase with new innovative products and services. Furthermore, we strongly advocate cost-reduction programs should not be associated with erosion of quality of care provided.

We observed existence of significant limitations in this analysis. The costs from one institution to another, especially between different countries for the institutional costs, costs to the patient, and costs for third-party payers, whether government or private insurance companies, may be very different for the same procedure [13]. It is also important to note that the data from the single institution examined in this study may not reflect the charges at other institutions in China, although we believe that it is representative of charges that may be encountered at other institutions.

Zhang et al. [13] analyzed charge data in China and found the charges are what the patient experiences as the costs of the procedure. Importantly, the patients in China who were covered by medical insurance 2 years ago were responsible for about half of all charges (insurance reimbursement covered approximately 8000 to 9000 yuan for the prosthesis and approximately $80 \%$ of other charges). However, in some cases, the patient had no medical insurance, and in these cases, the patient was responsible for most of the charges. It is important to note that the total charges for total joint arthroplasty noted in the study significantly exceeded the reimbursement for these procedures from medical insurance in China of approximately 8100 yuan for hip arthroplasty and 9000 yuan for knee arthroplasty.

Consequently, the substantial out-of-pocket costs in China are predominantly generated by only 2 categories, with approximately $80 \%$ of all charges attributed to the prosthesis and pharmacy charges and each patient is responsible for some out-of-pocket expenses, whether or not they have medical insurance coverage. According to a survey report by the World Health Organization in 2002, a patient in China was responsible for approximately $40 \%$ of hospital charges in 1992 and $62 \%$ in 2002; by comparison, this figure was $25 \%$ for patients in Thailand, $20 \%$ in Brazil, $11 \%$ in Germany, and $10.3 \%$ in Russia .Therefore, it is clear that the relative out-of-pocket costs for patients in China were 2 to 6 times higher than that for patients in other countries [13]. As a result, some patients in China, who are medical candidates for total joint arthroplasty, may not have access to care because of the relatively high financial barrier. This may result in decreased quality of life for the patient and their families and increased societal costs, such as lost worker productivity; in addition, there may be a negative effect on the development of medical services in China. Hence it is important to note that significant patient benefits may be realized by efforts to reduce the cost of the prosthesis and pharmacy items in China.

Total joint arthroplasty is intended to relieve pain and improve function for approximately 10 to 20 years, thus 10 -year evaluations are required to demonstrate improvements in total joint arthroplasty [19]. When a surgeon performs a joint replacement, his or her primary concern is to provide the best possible patient outcome in terms of pain relief, improved function, and durability of the reconstruction. So, the surgeons should use "best" implants that will give their patients predictably successful long-term outcomes with functional improvement that meets their expectations regardless of cost. It should be noted that for every joint replacement operation, clinical quality is the first priority. Fiscal responsibility is a secondary concern, but it is important.

Additional research is needed to address these important aspects of the long-term management of individuals with joint replacement the demand for total joint replacement is likely to continue to increase in coming decades and will be amplified further with a growing population of individuals undergoing revision surgery. Such a large increase in demand is unprecedented and must be addressed with effective planning of health-care services for these individuals, not only during the perioperative period but throughout the lifelong continued care of this population [25].

\section{Conclusions}

With the ageing of the population, the incidence of hip osteoarthritis (OA) in China is rising year by year and the number of Total Hip arthroplasty procedures performed annually is growing rapidly. We observed the substantial rise in procedure volume and an unprecedented rise in the incidence was predicted in coming years. The implant cost being the largest single expense was rising yearly and it strongly correlated with total in hospital cost. Despite the demand, concerns exist that the costs of these procedures may represent a significant barrier to care, with patients potentially unable to gain access to joint arthroplasty. Much is currently being done and several methods have been described by different authors to make total joint arthroplasty more cost effective. The hospital stay was significantly reduced and early discharge within 3 days postoperatively. We considered this finding as a significant achievement and a noteworthy outcome and we assume the THA may become a day surgery in near future.

\section{Abbreviations}

$\mathrm{OA}$

Osteoarthritis

THA

Total Hip Arthroplasty 
Tranexamic acid

\section{Declarations}

\section{Ethics approval and consent to participate}

This retrospective cohort study was approved by the Institutional Review Board of West China Hospital, Sichuan University. The work was registered in the Chinese Clinical Trial Registry, (ID number: ChiCTR2000028873).

\section{Consent for publication}

Not applicable

\section{Availability of data and material}

The datasets used and/or analysed during the current study are available from the corresponding author on reasonable request.

\section{Competing interests}

The authors declare that they have no competing interests.

\section{Funding}

This research did not receive any specific grant from funding agencies in the public, commercial, or not-for-profit sectors.

\section{Authors' contributions}

MY and HS performed data collection and analysis and manuscript writing. ZZK and HYW performed data analysis. ZL and KX helped to draft the manuscript. All authors reviewed the final manuscript. All authors agree to be accountable for all aspects of the work.

\section{Trial registration}

ChiCTR, ChiCTR2000028873. Registered 5 January 2020

\section{Acknowledgement}

The authors would like to express their appreciation to Mr.Hirdaya Ratna Shakya M.Sc. for his guidance and expert opinion regarding the improving of this manuscript.

\section{References}

1. Ethgen $O$, Bruyère $O$, Richy $F$, Dardennes $C$, Reginster J-Y. Health-related quality of life in total hip and total knee arthroplasty: a qualitative and systematic review of the literature. JBJS. 2004;86:963-74.

2. Räsänen P, Paavolainen P, Sintonen H, Koivisto A-M, Blom M, Ryynänen O-P, et al. Effectiveness of hip or knee replacement surgery in terms of quality-adjusted life years and costs. Acta Orthop. 2007;78:108-15.

3. Jones CA, Beaupre LA, Johnston DWC, Suarez-Almazor ME. Total joint arthroplasties: current concepts of patient outcomes after surgery. Rheumatic Disease Clinics of North America. 2007;33:71-86.

4. Coventry MB, Beckenbaugh RD, Nolan DR, Ilstrup DM. 2,012 total hip arthroplasties: a study of postoperative course and early complications. JBJS. 1974;56:273-84.

5. Harris WH, Sledge CB. Total hip and total knee replacement. N Engl J Med. 1990;323:725-31. 
6. Mihalich RM, Incavo SJ, Martell J, Coughlin K, Beynnon B. Simultaneous bilateral total hip arthroplasty with a cementless femoral stem. American journal of orthopedics (Belle Mead NJ). 2005;34:177-82.

7. Cammisa JF, O'brien SJ, Salvati EA, Sculco TP, Wilson JP, Ranawat CS, et al. One-stage bilateral total hip arthroplasty. A prospective study of perioperative morbidity. The Orthopedic clinics of North America. 1988;19:657-68.

8. Total Hip Replacement. NIH Consens Statement. 1994 September 12-14;12(5):1-31. 1994. https://consensus.nih.gov/1994/1994hipreplacement098html.htm.

9. Beringer DC, Patel JJ, Bozic KJ. An overview of economic issues in computer-assisted total joint arthroplasty. Clinical Orthopaedics Related Research®. 2007;463:26-30.

10. Hyattsville. National Center for Health Statistics Hyattsville. National Center for Health Statistics. Health US. 2009: With Special Features on Medical Technology. In: Health, United States, 2009 with Special Features on Medical Technology. DHHS Publication No. 2010 - 1232; 2010. https://www.cdc.gov/nchs/data/hus/hus09.pdf.

11. Kurtz S, Mowat F, Ong K, Chan N, Lau E, Halpern M. Prevalence of primary and revision total hip and knee arthroplasty in the United States from 1990 through 2002. JBJS. 2005;87:1487-97.

12. Huang S-L, He X-J, Wang K-Z. Joint replacement in China: progress and challenges. Oxford University Press; 2012.

13. Zhang Y, Zhang H, Clarke HD, Hattrup SJ. Analysis of total joint arthroplasty costs in Chinese patients. J Arthroplast. 2012;27:1423-8.

14. Kurtz SM, Lau E, Ong K, Zhao K, Kelly M, Bozic KJ. Future young patient demand for primary and revision joint replacement: national projections from 2010 to 2030. Clinical Orthopaedics Related Research®. 2009;467:2606-12.

15. Ong KL, Mowat FS, Chan N, Lau E, Halpern MT, Kurtz SM. Economic burden of revision hip and knee arthroplasty in Medicare enrollees. Clinical Orthopaedics Related Research®. 2006;446:22-8.

16. Kurtz S, Ong K, Lau E, Mowat F, Halpern M. Projections of primary and revision hip and knee arthroplasty in the United States from 2005 to 2030. Jbjs. 2007;89:780-5.

17. Bozic KJ, Kurtz SM, Lau E, Ong K, Vail TP, Berry DJ. The epidemiology of revision total hip arthroplasty in the United States. J Bone Joint Surg Am. 2009;91:128-33.

18. Healy WL, Finn D. The hospital cost and the cost of the implant for total knee arthroplasty. A comparison between 1983 and 1991 for one hospital. The Journal of bone joint surgery American volume. 1994;76:801-6.

19. Healy WL, Iorio R. Implant selection and cost for total joint arthroplasty: conflict between surgeons and hospitals. Clinical Orthopaedics Related Research®. 2007;457:57-63.

20. Bourne RB, Kim PR. Cost effectiveness of total hip arthroplasty. The adult hip Philadelphia: Lippincott-Raven. 1998;:839-44.

21. Laupacis A, Bourne R, Rorabeck C, Feeny D, Wong C, Tugwell P, et al. The effect of elective total hip replacement on health-related quality of life. The Journal of bone joint surgery American volume. 1993;75:1619-26.

22. Rorabeck CH, Bourne RB, Laupacis A, Feeny D, Wong C, Tugwell P, et al. A double-blind study of 250 cases comparing cemented with cementless total hip arthroplasty. Cost-effectiveness and its impact on health-related quality of life. Clinical orthopaedics and related research. 1994;:156-164.

23. Rorabeck CH, Murray P. The cost benefit of total knee arthroplasty. Orthopedics. 1996;19:777-9.

24. Mendenhall S. Hip and knee implant review. Orthopaedic Network News. 2011;22:1-3.

25. Maradit Kremers H, Larson DR, Crowson CS, Kremers WK, Washington RE, Steiner CA, et al. Prevalence of Total Hip and Knee Replacement in the United States. J Bone Joint Surg Am. 2015;97:1386-97.

26. Hawker GA, Wright JG, Coyte PC, Williams Jl, Harvey B, Glazier R, et al. Differences between men and women in the rate of use of hip and knee arthroplasty. N Engl J Med. 2000;342:1016-22.

27. Kurtz S, Lau E, Halpern M, Ong K. Trend shows growing orthopedic surgery case load. Will surgeons be able to keep up? Materials management in health care. 2006;15:61-2.

28. 28.

29. Barber TC, Healy WL. The hospital cost of total hip arthroplasty. A comparison between 1981 and 1990. The Journal of bone joint surgery American volume. 1993;75:321-5.

30. Boardman DL, Lieberman JR, Thomas BJ. Impact of declining reimbursement and rising hospital costs on the feasibility of total hip arthroplasty. J Arthroplast. 1997;12:526-34.

31. Clark CR. Cost containment: total joint implants. JBJS. 1994;76:799-800.

32. Meyers SJ, Reuben JD, Cox DD, Watson M. Inpatient cost of primary total joint arthroplasty. J Arthroplast. 1996;11:281-5.

33. Stern SH, Singer LB, Weissman SE. Analysis of hospital cost in total knee arthroplasty. Does length of stay matter? Clinical orthopaedics and related research. 1995;:36-44. 
34. Heiner DE, Mauerhan DR, Masonis JL, Heath J. Patient out-of-pocket expenses in major orthopedic procedures: total hip arthroplasty as a case study. J Arthroplast. 2008;23:509-14.

35. Chiu H-C, Shi H-Y, Mau L-W, Wang G-J. The effects of a prospective case payment system on hospital charges for total hip arthroplasty in Taiwan. J Arthroplast. 2007;22:65-71.

36. Cole BJ, Flic S, Levine DB. Optimizing hospital reimbursement through physician awareness: a step toward better patient care. Orthopedics. 1998;21:79-83.

37. Johnson CC, Martin M. Effectiveness of a physician education program in reducing consumption of hospital resources in elective total hip replacement. Southern medical journal. 1996;89:282-9.

38. Levine DB, Cole BJ, Rodeo SA. Cost awareness and cost containment at the Hospital for Special Surgery. Strategies and total hip replacement cost centers. Clinical orthopaedics and related research. 1995;:117-124.

39. Zuckerman JD, Kummer FJ, Frankel VH. The effectiveness of a hospital-based strategy to reduce the cost of total joint implants. The Journal of bone joint surgery American volume. 1994;76:807-11.

40. Iorio R, Healy WL, Kirven FM, Patch DA, Pfeifer BA. Knee implant standardization: an implant selection and cost reduction program. Am J Knee Surg. 1998;11:73-9.

41. Healy WL. Economic considerations in total hip arthroplasty and implant standardization. Clinical orthopaedics and related research. 1995;:102-108.

42. Healy WL, Kirven FM, lorio R, Patch DA, Pfeifer BA. Implant standardization for total hip arthroplasty: an implant selection and a cost reduction program. J Arthroplast. 1995;10:177-83.

43. Healy WL, lorio R, Lemos MJ, Patch DA, Pfeifer BA, Smiley PM, et al. Single price/case price purchasing in orthopaedic surgery: experience at the Lahey Clinic. JBJS. 2000;82:607.

44. Healy WL. Gainsharing: a primer for orthopaedic surgeons. JBJS. 2006;88:1880-7.

45. DeJohn P. Price survey: buyers aim to cap hip prices. Hospital Materials Manager. 2005;30:10-2.

46. Luo Z-Y, Wang H-Y, Wang D, Zhou K, Pei F-X, Zhou Z-K. Oral vs intravenous vs topical tranexamic acid in primary hip arthroplasty: a prospective, randomized, double-blind, controlled study. J Arthroplast. 2018;33:786-93.

\section{Figures}

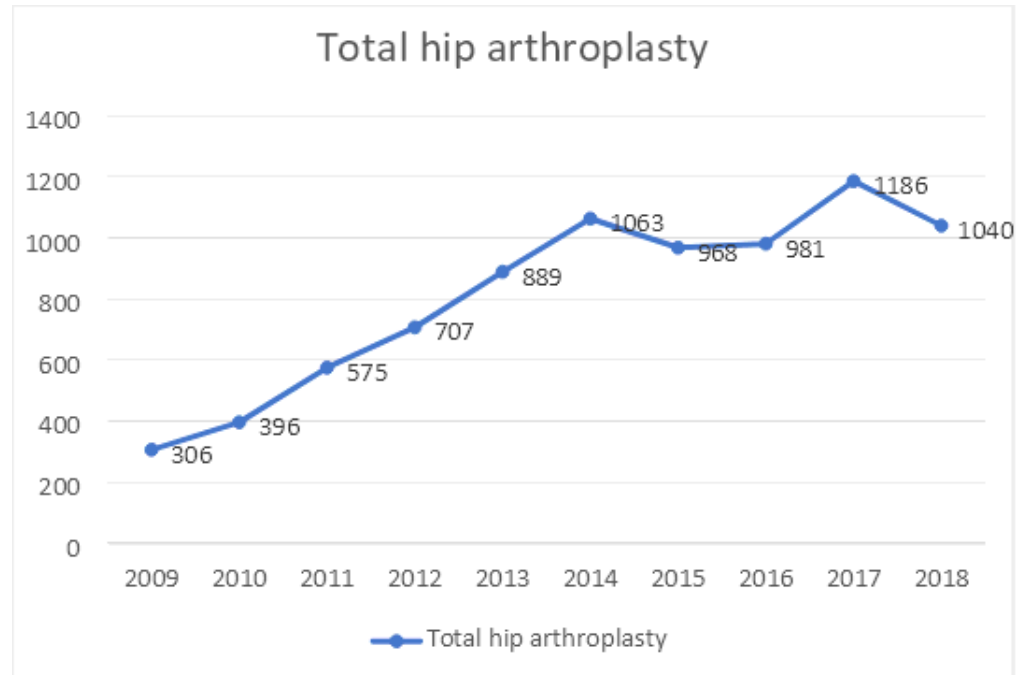

\section{Figure 1}

Annual procedure volume 